\title{
Los profesores universitarios en el Nuevo Cine Español: representaciones y prototipos en Nueve cartas a Berta (Basilio Martín Patino, 1966)
}

\section{Resumen}

La Universidad española no ha tenido mucha presencia en el cine español del franquismo (1939-1975) hasta la década de los 60. El número de universitarios experimentó un cierto crecimiento desde la década anterior, y así se empezó a plasmar en la pantalla grande a partir de estos años. La capacidad del cine para reflejar, representar y construir realidades permite que las películas ambientadas en el ámbito universitario muestren -de forma fiel, crítica o idealizada-, esa realidad educativa, además de las relaciones entre los docentes y los alumnos. De esta manera, los objetivos de este estudio son abordar la representación de la Universidad en el cine español de los años 60 y conocer los rasgos del profesor universitario en el Nuevo Cine Español, una corriente cinematográfica crítica con el cine hegemónico del franquismo. Para ello, se analiza a los docentes de Nueve cartas a Berta (1966), dirigida por Basilio Martín Patino, uno de los cineastas más personales de este estilo. Desde estas consideraciones, se pretende reflexionar sobre los prototipos de profesor universitario presentes en el cine español de los 60 y conocer sus semejanzas y diferencias con los planteados en Muerte de un ciclista (Juan Antonio Bardem, 1955) que supuso la primera representación de la educación superior en el cine español-, y en películas comerciales como Margarita se llama mi amor (Ramón Fernández, 1961) y Los chicos del Preu (Pedro Lazaga, 1967).

Palabras clave: Profesor universitario. Nuevo Cine Español. Basilio Martín Patino. Franquismo. Personaje.

\author{
Valeriano Durán Manso \\ Universidad de Cádiz - Espanha \\ valeriano.duran@uca.es
}

\section{Para citar este artigo:}

MANSO, Valeriano Durán. Los profesores universitarios en el Nuevo Cine Español: representaciones y prototipos en Nueve cartas a Berta (Basilio Martín Patino, 1966). Revista Linhas. Florianópolis, v. 21, n. 47, p. 103-132, set./dez. 2020. 
University Professors in the New Spanish Cinema: Representations and prototypes in Nine Letters to Berta (Basilio Martín Patino, 1981)

\begin{abstract}
The Spanish University has not has much presence in the Spanish Cinema of Francoism (1939-1975) until the 1960s. The number of university students experienced a certain growth from the previous decade, and thus began to be captured on the big screen from these years. The capacity of cinema to reflect, represent and construct realities allows films set in the university environment to show -in a faithful, critical or idealized way-, that educational reality, in addition to the relationship between teachers and students. In this way, the objectives of this paper are to approach the representation of the University in Spain of the 1960s, to know the characteristics of the university profesor in the New Spanish Cinema, a cinematographic current critical of the hegemonic cinema of Francoism. For this, the teachers of Nueve cartas a Berta (1966), directed by Basilio Martín Patino, one of the most personal filmmakers of this style, are analyzed. From these considerations, it is intended to reflect on the prototypes of a university profesor in the Spanish cinema in the196os and to know its similarities and differences with those proposed in Muerte de un ciclista (Juan Antonio Bardem, 1955) -which was the first representation of higher education in Spanish cinema-, and in comercial films such as Margarita se llama mi amor (Ramón Fernández, 1961) and Los chicos del Preu (Pedro Lazaga, 1967).
\end{abstract}

Keywords: University Professor. New Spanish Cinema. Basilio Martín Patino. Francoism. Character.
Professores universitários do Novo Cinema Espanhol: representaçôes e prototipos em Nove cartas para Berta (Basilio Martín Patino, 1966)

\section{Resumo}

A Universidade española no não teve grande presença no cinema espanhol do regime de Franco (1939-1975) até a década de 1960. O número de estudantes universitários teve um certo crescimento desde a década anterior, e assim começou a se refletir na tela a partir desses anos. A capacidade do cinema de refletir, representar e construir realidades permite que os filmes ambientados no cambiente universitário mostrem - com fidelidade, crítica ou idealidade -, essa realidade educacional, além das relaçoes entre professores e alunos. Dessa forma, os objetivos desde estudo são abordar a representação da Universidade do cinema espanhol dos anos 60 e conhecer as características do profesor universitário no Novo Cinema Espanhol, uma corrente cinematográfica crítica do cinema hegemônico do franquismo. Para isso, são analisados os professores de Nove cartas para Berta (1966), dirigido por Basilio Martín Patino, um dos cineastas mais pessonais desse estilo. A partir dessas considerações, pretende-se refletir sobre os prototipos de profesor universitário presentes no cinema espanhol dos anos 60 e conhecer suas semelhanças e diferenças com os levantados em Morte de um ciclista (Juan Antonio Bardem, 1955) - que foi a primeira representação do ensino superior do cinema español -, e em filmes comerciais como Margarita se chama meu amor (Ramón Fernández, 1961) e Os meninos do Preu (Pedro Lazaga, 1967).

Palavras-chave: Professor universitário. Novo Cinema Espanhol. Basilio Martín Patino. Franquismo. Personagem. 


\section{Introducción}

La figura del profesor universitario ha tenido una escasa presencia en el cine español durante el franquismo (1939-1975), mientras que, paralelamente, en cinematografías como la norteamericana sí se producían películas centradas en la Universidad y en las relaciones entre los docentes y los alumnos (MILLÁN y PÉREZ MORÁN, 2015). A partir de la década de los 50, y especialmente en la de los 60, el ámbito académico empezó tener una mayor visibilidad en la gran pantalla española, sobre todo a través de películas enmarcadas en la comedia o en el cine musical. Algunas de las protagonizadas por los considerados niños prodigio, como Joselito, Marisol o Rocío Dúrcal, transcurrían en entornos educativos como colegios o internados-sobre todo las de las dos últimas (DURÁN MANSO, 2015)-, donde la figura del maestro, del profesor o del instructor tenía una gran relevancia. Por ello, las tramas y los personajes conectaban mejor con el público infantil o juvenil al que se dirigían. Asimismo, y aunque no se centraban en la Universidad, esta institución era mencionada en estos filmes como un espacio superior para la formación, la cultura, la elite y el futuro de la sociedad, especialmente para los chicos. Así se observa en Canción de juventud (Luis Lucia, 1961), protagonizada por Rocío Dúrcal, donde los jóvenes manifiestan sus aspiraciones universitarias y las chicas no, a pesar de estar estudiando en un selecto internado religioso femenino de la exclusiva Costa Brava.

En cierto sentido, mencionar o tratar el ámbito universitario en las películas de los ídolos juveniles del cine comercial de los años del desarrollismo respondía también al interés que tenía el régimen de dar una imagen de modernidad ante Europa a través del cine. Además, al hablar de la Universidad, aparecían en los filmes personajes vinculados a la burguesía de Madrid o de las ciudades de provincias, o, también, otros del mundo rural que hacían un esfuerzo por poder dar a sus hijos carreras universitarias. De esta manera, la Universidad parecía ligada en estos años a un cierto aperturismo y transmitía la idea, al menos a través del cine comercial, de que la clase media, y no solo la elite social, podía acceder a los estudios superiores. Además, en su afán de modernidad para obtener el definitivo reconocimiento internacional en Europa, desde finales de los 50 la dictadura se planteaba "la creación de un cine técnicamente moderno, que pudiera competir con el europeo y a la vez ser controlado por el Estado" (ARAGÜEZ RUBIO, 2006, p. 79). Con ello, 
se atisbaba el compromiso del régimen por desarrollar la industria del cine de cara al extranjero, eso sí ejerciendo su influencia en los títulos y en los temas. Así, "en este contexto histórico y político comenzaron a desarrollarse películas que no necesariamente se ajustaban a la ideología más próxima del gobierno y que, del mismo modo, proponían una renovación del medio" (SÁNCHEZ RODRÍGUEZ, 2016, p. 69). La mayoría de ellas estarían enmarcadas en el Nuevo Cine Español (NCE) y serían críticas con el poder y con la sociedad, al abordar aspectos tradicionalmente censurados.

Estas películas se acercarían al ámbito educativo de una forma menos edulcorada que el cine comercial, es decir, con un tono más realista. Así lo demuestran las de uno de los directores más representativos de esta corriente, Basilio Martín Patino, cuya ópera prima, Nueve cartas a Berta (1966), centra el presente trabajo al estar protagonizada por Lorenzo, un estudiante de Derecho de la Universidad de Salamanca -la ciudad universitaria española por antonomasia-, desarrollarse en esta capital castellana, mostrar varios perfiles de profesores y de estudiantes, y exhibir los conflictos familiares en torno al futuro de los jóvenes de la época. Además, a partir de esta película, Salamanca se convierte en el "topos por excelencia de la filmografía de Patino" (MONTES ESPEJO, 2015, p. 440). Desde estas consideraciones, se plantean como objetivos abordar la representación de la Universidad en el cine español de la década de los 60, reflexionar sobre el contexto y las aportaciones del Nuevo Cine Español y analizar el primer filme de Patino desde la perspectiva de la educación universitaria, atendiendo a los diferentes tipos de docentes, a los perfiles de alumnos y de alumnas, y al papel que ocupa Salamanca como espacio de una sociedad tan marcada por las pautas del franquismo como por la influencia de su Universidad. Así, se pretende evidenciar las semejanzas y las diferencias existentes entre el tratamiento del profesorado universitario en el cine español comercial de los 60 y en el NCE. Para ello, se sigue la metodología de estudio de caso (MARTínEZ CARAZO, 2006), pues Nueve cartas a Berta se considera una película muy representativa de la realidad universitaria de la citada década y, también, es una de las más emblemáticas del NCE. 


\section{Fidelidad y oposición al franquismo en el cine de los años 50 y 60}

La década de los 50 fue decisiva en el desarrollo del cine español hacia nuevos caminos más realistas y críticos. Aunque el ideario del franquismo seguía vigente en el cine hegemónico, se empezaron a percibir ciertos aires de cambio que se materializarían en la década siguiente, principalmente a través del NCE. Los géneros narrativos más desarrollados en los años 50 -tras la serie de cine histórico, patriótico y nacionalcatólico impulsado por el régimen en los años 40 (DURÁN MANSO y ÁLVAREZ DOMÍNGUEZ, 2018), eran el melodrama -que obtuvo un considerable desarrollo con las películas que protagonizó Sara Montiel a partir del triunfo de El último cuplé (Juan de Orduña, 1957) (MONTERDE, 2005, p. 271)-, la comedia y el cine con niño, que constituyeron la base del cine comercial de la época. De los tres, la comedia fue la protagonista, llegando a estar presente en los otros dos, especialmente en el cine con niño. Se trataba de un género que tenía una patente finalidad de evasión y que en numerosas ocasiones contenía canciones interpretadas por los propios actores, quienes a veces eran cantantes, como se produjo a finales de los años 60 con las exitosas películas protagonizadas por la actriz Concha Velasco y por el cantante Manolo Escobar. Los filmes de este género solían mostrar de forma amable el estilo de vida, la sociedad y los ideales que propugnaba el franquismo, como también se produjo en los taquilleros títulos de los niños prodigio.

El primero de ellos, Pablito Calvo, fue precisamente el que menos recorrido tuvo en la década de los 60, aunque su arrollador éxito, tanto nacional como internacional, con Marcelino, pan y vino (Ladislao Vajda, 1954) lo convirtió en el prototipo para los demás. Así, Joselito, que, fue el siguiente en aparecer con el filme El pequeño ruiseñor (Antonio del Amo, 1956), poseía también su imagen angelical, su pequeña estatura y su simpatía. Sin embargo, la cualidad por la que destacaba no había sido explotada por Calvo y fue la que determinó la personalidad del subgénero de cine con niño: la voz. De esta manera, la incorporación de canciones interpretadas por los niños actores durante la acción se convirtió en la seña de identidad de los posteriores ídolos creados por el régimen. Marisol y Rocío Dúrcal fueron quienes mejor representaron el concepto desde que debutaron con Un rayo de luz (Luis Lucia, 1960) y Canción de juventud, respectivamente, desarrollando, además, exitosas carreras musicales con las canciones de sus películas. Por otra parte, este 
subgénero representó también distintos espacios escolares, ya que las películas de Joselito mostraban la educación en el mundo rural; las de Rocío Dúrcal, la de zonas urbanas y elitistas; y las de Marisol combinaban diversos tipos, al encarnar tanto a niñas de origen humilde como de elevada posición (DURÁN MANSO, 2015). Esto conllevó también la plasmación de maestros rurales, institutrices y monjas docentes en la gran pantalla.

Las películas de estos géneros narrativos proyectaban los valores del régimen y a partir de los 60 empezaron a reflejar el desarrollo de la clase media, el auge del turismo y el acceso a la Universidad tanto de chicos como de chicas. De esta manera, el cine comercial de la época desempeñó un notable papel como difusor de la propaganda del desarrollismo. Sin embargo, a pesar del control de la industria por parte de la dictadura, desde principios de los 50 hubo voces discordantes que pretendían plantear una crítica social y política en sus películas:

En algunos casos esa voluntad de cambio tenía una motivación de carácter explícitamente político, como en las emblemáticas figuras de Juan Antonio Bardem, Ricardo Muñoz Suay o Eduardo Ducay, orgánica e intensamente vinculados al PCE; en otros casos, como Luis García Berlanga, nunca hubo adscripción política, aunque fueron numerosos los que integrarían las filas de los llamados 'compañeros de viaje', que con mayor o menor conciencia contribuyeron a determinadas formas de resistencia antifranquista. (MONTERDE, 2005, p. 278-279)

Bardem y García Berlanga consiguieron ofrecer una mirada más crítica y realista de la sociedad española, pues, recurriendo al humor y al sarcasmo, lograron evitar los estragos de la censura de carácter católico y moralizante imperante (GIL, 2009). Así ocurrió en el primer filme que rodaron, Esa pareja feliz (1951), y, sobre todo, en Bienvenido, Míster Marshall (1953), que dirigió el segundo y tuvo al primero entre sus guionistas. La senda iniciada por ambos cineastas, así como por otros como José Antonio Nieves Conde -quien realizó en la neorrealista Surcos (1951) un duro retrato de la emigración del campo a la ciudad-, se sumarían a finales de los 50 directores que formarían parte del NCE, como Carlos Saura, Manuel Summers, Miguel Picazo o Basilio Martín Patino, como se explicará más adelante. Asimismo, estas tendencias críticas y contestatarias aparecerían también planteadas en los títulos de la vanguardista y experimental Escuela de Barcelona y, 
posteriormente, en el tardofranquismo, con el cine de la Tercera Vía (TORREIRO, 2005), en ambos casos desde el drama.

Uno de los acontecimientos que reflejaron la necesidad de fortalecer la industria fílmica española fueron las Conversaciones de Salamanca, celebradas en mayo de 1955 y organizadas "por el cine-club del SEU de Salamanca, [... ] con el apoyo del rectorado y el soporte activo de la revista Objetivo, creada en julio de 1953" (MONTERDE, 2005, p. 282). De esta manera, la propia Universidad de Salamanca respaldaba una iniciativa que fue dirigida por Basilio Martín Patino, quien aún no había concluido sus estudios de cine. Estas jornadas, que fueron esenciales para evidenciar la situación en la que estaba el cine español, "pretendían la renovación cultural y cinematográfica del momento" (SÁNCHEZ RODRÍGUEZ, 2016, p. 71). Así, reunieron tanto a directores próximos al régimen como a otros más críticos -“desde militantes clandestinos del PCE hasta falangistas no acomodados al franquismo" (MONTERDE, 2005, p. 282)-, e incluso a jóvenes aún desconocidos, y recogieron aspectos como la reivindicación del cine como forma de expresión cultural -y no solo como medio para la evasión-, la defensa de la tradición realista y la apuesta por un cine que abandonara el aislamiento y que pudiera resultar competitivo en el ámbito internacional. Asimismo, las conversaciones "también marcaron un giro decisivo en la evolución del cine español como punto de partida teórico de lo que se conoce como Nuevo Cine Español” (SÁNCHEZ RODRíGUEZ, 2016, p. 73). A este respecto, algunas de las iniciativas planteadas en esta cita se empezaron a materializar siete años más tarde, a partir de 1962, en las películas adscritas al NCE, como se observa en Nueve cartas a Berta.

\section{La Universidad en el cine de Juan Antonio Bardem y en el cine comercial}

El ámbito universitario no apareció en la gran pantalla española hasta la década de los 50, a pesar de que otros espacios educativos sí eran representados. En este sentido, durante la posguerra se estrenaron filmes que se desarrollaban en escuelas rurales, como A mí no me mire usted (José Luis Sáenz de Heredia, 1941) y Forja de almas (Eusebio Fernández Ardavín, 1943), o en internados, como Pequeñeces (Juan de Orduña, 1950) 
(DURÁN MANSO y ÁLVAREZ DOMÍNGUEZ, 2018). Sin embargo, en estos años la Universidad no estaba representada en el cine, quizá porque resultaba algo alejada de un público popular de posguerra que consumía el cine comercial para poder evadirse de su realidad. La idea de que era una institución próxima a la elite social y cultural se mantuvo incluso en las primeras películas que la abordaron, pero en los años del desarrollismo se planteó un tratamiento de la misma más próximo a la clase media o a las clases populares que veían que si sus hijos estudiaban una carrera podrían prosperar. De esta manera, la imagen de la Universidad en el cine español del franquismo estuvo al principio vinculada a la elite para ir paulatinamente acercándose al gran público.

El género donde tuvo más desarrollo fue la comedia, especialmente en los años 60, al ser el que más éxito tenía en el público. Así, algunos de los actores del momento, como Alberto Closas, Amparo Soler Leal, José Luis López Vázquez o Mary Carrillo, y otros jóvenes como Mercedes Alonso, Manolo Zarzo, Jaime Blanch, María José Goyanes o Emilio Gutiérrez Caba, acercaron las experiencias universitarias, o preuniversitarias, a los espectadores, con sus roles de progenitores, profesores o alumnos. Esta presencia de intérpretes tan conocidos favorecía el proceso de identificación con los personajes que encarnaban.

Además, en las escenas aparecían clases de diversas asignaturas y en los diálogos se mencionaban diferentes carreras o sus salidas profesionales, de manera que el público podía familiarizarse con el ámbito universitario que se plasmaba en las películas comerciales. No obstante, debido a los propios códigos de la comedia se mostró una imagen determinada de la Universidad, más próxima a las pocas ganas de estudiar de los jóvenes, a sus amores con compañeros de clase y a los conflictos con sus padres, que a las oportunidades culturales, académicas y profesionales que proporcionaba la institución, algo que sí aparecía en las películas de los directores más críticos con el régimen. Por ello, la mirada que un cineasta como Juan Antonio Bardem ofreció de la Universidad en Muerte de un ciclista (1955), la primera película que la representó en el franquismo, resultó totalmente diferente de la que ofrecieron las comedias populares de los 60. 
Protagonizada por Alberto Closas y por Lucía Bosé, la película de Bardem se centraba principalmente en la relación adúltera que mantienen Juan y María José, y en el tormento que sufren tras atropellar de forma mortal a un ciclista cuando volvían de uno de sus encuentros. A pesar de que la historia muestra la culpabilidad que sienten y el temor a ser descubiertos, pues ambos pertenecen a la alta sociedad de Madrid, la Universidad tiene una notable presencia. El protagonista es profesor adjunto de Geometría Analítica y ocupa el cargo tanto por su talento como por sus relaciones familiares, lo que evidencia la endogamia presente en la institución.

El estrés que sufre tras el accidente -pues ni él ni María José socorrieron a la víctima, lo lleva a enfrentarse a Matilde -una de sus más brillantes alumnas y una de las pocas que hay en la clase-, mientras estaba haciendo un examen oral en presencia de todos sus compañeros. Esto permite ver cómo eran este tipo de pruebas en esta época, el mobiliario de la clase tipo anfiteatro o la relación distante entre profesores y alumnos, algo que se enfatiza cuando la joven va a reclamar su nota al despacho, pues la ha suspendido injustamente. Asimismo, también aparecen espacios exteriores del campus, como las zonas deportivas o la fachada de la facultad, donde los alumnos protestan contra Juan por la injusticia cometida con Matilde y lanzan objetos que rompen un cristal. La manifestación es similar "a las que empezaban a producirse en realidad en aquellos años, aunque teniendo que disfrazarla de motivaciones puramente académicas, porque de lo contrario no habría superado el filtro censor" (PÉREZ MILLÁN y PÉREZ MORÁN, 2016, p. 67).

Esta secuencia simboliza el primer acto de protesta contra el poder establecido que apareció en una película española durante el franquismo, resultando una metáfora planteada por Bardem sobre lo que pueblo debía hacer contra la dictadura. Por estos motivos, resulta una película muy representativa, pues cuenta con diversos personajes ligados a la Universidad, tanto profesores como estudiantes; se desarrolla en espacios interiores y exteriores de una facultad; y recrea tres de las acciones que tienen lugar en esta institución, como la celebración de los exámenes, las reclamaciones en los despachos o las manifestaciones de los estudiantes.

El tratamiento dramático y profundo sobre la Universidad que presenta Muerte de un ciclista no se produce en las comedias más comerciales. Así, en Margarita se llama mi 
amor (Ramón Fernández, 1961), protagonizada por la joven estudiante Margarita Rodríguez Garcés -interpretada por Mercedes Alonso-, la acción gira en torno a las experiencias estudiantiles y amorosas de los personajes. El aspecto más significativo de la película en cuanto a la realidad universitaria de la época, es su apuesta por situar a la mujer en la institución, sobre todo cuando su presencia aún era escasa a principios de los 60 . Por ello, aparecen aulas repletas de alumnos y muy pocas alumnas.

Asimismo, pertenecen a familias acomodadas que pueden sufragar sus carreras y, lo que es más interesante, que creen que deben proporcionar a sus hijas las mismas oportunidades educativas que a sus hijos. Margarita estudia en la Facultad de Filosofía y Letras de la Universidad Complutense, tiene una elevada posición social y posee rasgos que la definen como una mujer moderna, pues estudia en la Universidad y conduce su coche, que, además es un descapotable de color rojo. A este respecto, estudiar y conducir son dos aspectos vinculados con la independencia y la libertad de la mujer. Aunque el filme acentúa el atractivo físico de la joven y se centra en aspectos narrativos propios de la comedia pues varios de sus compañeros la pretenden y ella está enamorada de su profesor de Literatura-, resulta interesante por ser la primera película española destinada al gran público con una protagonista universitaria.

Por su parte, Los chicos del Preu (Pedro Lazaga, 1967) se centra en las aspiraciones de un heterogéneo grupo de jóvenes preuniversitarios. Con filmes como La ciudad no es para mí (1965), además de otras comedias, Lazaga se había convertido en el cineasta más taquillero de la década (ARAGÜEZ RUBIO, 2006, p. 89). Así, dotó a la película de ingredientes comerciales como los amores entre los personajes, los conflictos generacionales y la música, con un reparto coral compuesto por Emilio Gutiérrez Caba, Cristina Galbó y María José Goyanes, y cantantes como Karina y Camilo Sesto. La historia empieza con la llegada de Andrés -interpretado por Gutiérrez Caba-, a Madrid desde Tomelloso gracias a una beca. El mundo rural que deja atrás es radicalmente opuesto a la agitada vida de la capital, así que, a pesar del esfuerzo que realizan sus padres, el joven sucumbe a los atractivos de la ciudad. 
Sin embargo, más tarde compagina los estudios con un trabajo como mozo en un mercado, pues toma conciencia del sacrificio de su familia para que pueda ir a la Universidad. Junto a él aparecen jóvenes de diversos perfiles, desde el estudiante brillante, al pasota o al que le cuesta sacar nota, y en todos ellos acecha la sombra de hacer una carrera, unos porque lo desean y otros porque sus familias los obligan. A diferencia de otras películas de la época, el número de estudiantes está equilibrado entre chicos y chicas, pues, además, la cifra de alumnas que estudiaba el Preu y que después se matriculaban en la Universidad era mucho mayor que a principios de los 60. Asimismo, los estudiantes no solo proceden de ámbitos sociales elitistas, sino que también pertenecen a la clase media y a las clases humildes, como es el caso del protagonista. Esto indica que a finales de la década la gran pantalla decidió mostrar la Universidad de una forma accesible a los espectadores.

\section{El Nuevo Cine Español (NCE): un cierto espíritu de renovación}

El reconocimiento de Viridiana (Luis Buñuel, 1961) con la Palma de Oro del Festival de Cannes cuando había sido prohibida en España -incluso pidiéndose "la destrucción física del negativo y de las copias que se hubiesen obtenido" (BELLO CUEVAS, 2014, p. 28)-, marca un punto de inflexión en el cine español. Este galardón evidenciaba que la vanguardia fílmica era perseguida en España y que el cine comercial que apoyaba el régimen carecía de atractivo para los prestigiosos festivales internacionales. El escándalo que supuso el premio provocó la dimisión del ministro de Información y Turismo, Gabriel Arias Salgado, y del Director General del Cine, José María Muñoz Fontán, quienes fueron sustituidos en 1962, respectivamente, por Manuel Fraga Iribarne y por José María García Escudero, cuya imagen "era la de un intelectual comprometido con la evolución del cine español e implicado en la consecución de un panorama cinematográfico más serio, técnicamente moderno y estéticamente cercano a alguna de las tendencias ya consolidadas del cine europeo" (ARAGÜEZ RUBIO, 2006, p. 81). Con ambos, comenzó un periodo de cierto aperturismo (TORREIRO, 2005, p. 299), que iba a permitir en el cine el tratamiento de temas tradicionalmente condenados por el franquismo: 
Desde ese momento el término 'apertura' va a ser utilizado por el Régimen como lema propagandístico que paliara la carencia de libertades que él mismo imponía. Pronto la apertura va a comenzar a relacionarse con ciertos indicios, no solo de desarrollo econ6mico y social, sino también de modernizaci6n cultural. A partir de entonces se van a tomar medidas en distintos campos que proyecten, tanto interior como exteriormente, una imagen de progreso político y social, y de aumento de libertades. En definitiva, una imagen de apertura. Se trata, pues, de una clara estrategia de propaganda del Régimen para justificarse interiormente y legitimarse exteriormente con la vista puesta en el nuevo mapa europeo. (ARAGÜEZ RUBIO, 2006, p. 78)

A este respecto, la política de García Escudero dio lugar en 1963 a una Ley de Censura que por primera vez indicaba a los cineastas qué podía ser censurable y qué no, pues, hasta la fecha, las prohibiciones dependían de cada censor (BELLO CUEVAS, 2014, p. 29), aunque en la década de los 40 se fijaron una serie de parámetros. Con esta iniciativa, los cineastas tendrían más libertad temática, especialmente para reflejar aspectos de la realidad social, pero seguía “prohibido cualquier crítica a la política nacional, cualquier mención a la figura del Jefe de Estado y la justificación en pantalla de hechos considerados atentatorios contra la moral, tales como el adulterio, el incesto, el aborto o el suicidio" (ARAGÜEZ RUBIO, 2006, p. 84). Otra de las iniciativas de García Escudero estuvo ligada a la formación, y consistió en la conversión del Instituto de Investigaciones y Experiencias Cinematográficas (IIEC) -creado en 1947-, en la Escuela Oficial de Cinematografía (EOC), que contribuyó a favorecer la profesionalización del sector.

Asimismo, propició que las películas de los cineastas aquí formados reflejaran esta renovación bajo la denominación de Nuevo Cine Español (NCE), un propagandístico nombre que tenía una voluntad de ruptura con el cine más comercial y seguía la estela de Juan Antonio Bardem y de Luis García Berlanga, a pesar de que criticaban al régimen. Además, apostaba por la diversidad de géneros -inclinándose hacia el drama-, la superación del neorrealismo a partir del interés por el documentalismo y una temática de tipo realista, o la apuesta por un lenguaje más claro y explícito que suponía una colisión con la censura. Este cine, "que también hay que comprenderlo dentro de la renovación que, en todo el mundo, tiene lugar en la década de los sesenta, cuyo trasfondo es tanto 
sociopolítico como generacional” (SÁNCHEZ NORIEGA, 2005, p. 481”, tuvo su película inicial en Los golfos (Carlos Saura, 1959), surgida de la EOC.

Las jóvenes, y críticas, voces del NCE, como Jaime Camino, Mario Camus, José Luis Borau, Víctor Érice, Angelino Fons, Antonio Mercero, Basilio Martín Patino, Miguel Picazo, Carlos Saura, o Manuel Summers, se reflejaron en títulos tan destacados como Los farsantes (Camus, 1963), La tía Tula (Picazo, 1964), La niña de luto (Summers, 1964), La caza (Saura, 1965), Nueve cartas a Berta (Martín Patino, 1966) o La busca (Fons, 1966). En estas películas se evidencia la inspiración literaria de las óperas primas de algunos de estos cineastas, quienes recurrieron a autores clásicos como Miguel de Unamuno y Pío Baroja como se advierte en las adaptaciones de Picazo y de Fons, respectivamente-, pero sobre todo a los contemporáneos Juan García Hortelano, Daniel Sueiro, Ignacio Aldecoa o Juan Antonio Zunzunegui. En este sentido, "la novela de los 50, fundamentada en el realismo social o neorrealismo, será la que sirva en su mayoría de inspiración para el llamado Nuevo Cine Español, y serán los temas, más que la técnica o el lenguaje, aquello que absorba y realmente aporte influencias a este cine" (BRAVO, 2000, p. 146).

Así, el choque entre la vida rural y la ciudad, el trabajo, la desidia de la juventud burguesa, la desigualdad o el desarraigo de la sociedad, centraron unos relatos que poseían un espíritu de denuncia. Los filmes de esta tendencia solían tener más calidad argumental que los del cine comercial -donde destacaba la comedia-, y muchos constituyeron notables muestras de cine de autor, convirtiéndose en obras representativas del estilo de unos directores que solían crear también sus propios guiones. Aunque algunas participaron en festivales internacionales -como los de Berlín, Cannes, Venecia o San Sebastián-, fueron proyectadas en distintos países y obtuvieron diversos premios, se enfrentaron a cortes de censura para poder llegar a las salas comerciales españolas y solamente alcanzaron a una elite cultural:

Se trata de películas de un calado diferente, evolucionado, que parten desde una nueva forma de comprender el presente, impregnadas del nuevo espíritu que acompaña a sus directores, que pertenecen a una nueva generación desvinculada de factores atenazadores, y comprometida con el nuevo orden que nuestro país ha de tomar en su aproximación a lo moderno. [...] El nuevo cine habla de películas 
problemáticas alojadas sobre todo en los sectores juveniles de la sociedad reflejo de este nuevo orden de directores que buscan una vía de salida para dar cobijo a sus inquietudes, intelectuales y creativas. (SÁNCHEZ BOROX, 2015, p. 97-98)

De todas formas, "conviene aclarar que el NCE se distinguió mucho más por su enorme atipicidad con respecto al resto de cine producido en España, que por su permeabilidad para adoptar modelos narrativos importados del exterior" (TORREIRO, 2005, p. 309). Esta etapa se extendió hasta 1967, si se toma como fecha el cese de García Escudero, o 1969, que es cuando Fraga abandonó el Ministerio de Información y Turismo, por lo que solo comprende un periodo de entre cinco y siete años. A pesar de que no caló en el gran público como el cine comercial -que al ser calificado para todos los públicos Ilegaba a más salas-, el NCE supuso una alternativa de calidad en la gran pantalla española que obtuvo éxito internacional. Resulta curioso que un cine que para el régimen pretendía "representar la liberalidad, el bienestar y la calidad de las producciones en España se convierte en el reflejo del desarraigo, la amargura, el pesimismo, la abulia y la frustración de la vida cotidiana de sus habitantes" (BRAVO, 2000, p. 149). Por ello, sus títulos reflejan con más precisión la sociedad española de la época que el cine comercial, que, por el contrario, tenía un mayor respaldo del público.

\section{Análisis: la aportación de Basilio Martín Patino}

Como se mencionó anteriormente, Basilio Martín Patino impulsó las Conversaciones de Salamanca, y esta iniciativa lo situó en un lugar crítico con respecto al tipo de cine hegemónico de la época. Su interés por plasmar el desencanto de la sociedad en la gran pantalla, lo llevó a desarrollar labores de dirección y de guion para presentar historias en las que los protagonistas están experimentando una búsqueda interior ante la realidad que les rodea. Por ello, algunos de ellos presentan una serie de inquietudes y dudas que, posiblemente, respondían a las del propio cineasta. 
En este sentido, en sus primeras películas se refleja "el desasimiento del personaje con respecto a un pasado más o menos inmediato, a unas convenciones dadas en las que ya no cree", de manera que "la motivación guía va a ser la necesidad del personaje principal de reestructurar su comprensión de la realidad" (GONZÁLEZ GARCíA, 1997, pp. 141-142). Estas palabras se dan cita especialmente en el protagonista de Nueve Cartas a Berta, la película con la que debutó en 1966. Este filme supuso una novedad con respecto al cine imperante del franquismo, y no solo en lo relativo al tema que trataba, sino también al tono, pues Martín Patino le imprimió un estilo documental -presente en los cortometrajes que había realizado-, que resultó tan oportuno y moderno como poco habitual en las pantallas de los 60:

Empujado por la censura o por la no menos dura realidad de aquella escuálida industria de la época, el caso es que fiel a esa idea del juego, Patino realiza su primer largometraje Nueve cartas a Berta, en el año 1965. La película de Basilio se integra enseguida, en un destacadísimo lugar, en la excelente cosecha que produce la cinematografía española en torno a ese año (Carlos Saura estrena La caza; Miguel Picazo, La tía Tula; Mario Camus, Young Sánchez, y Angelino Fons, La busca). [... ] Extramuros de esta España opaca y gris funcionan otras etiquetas: la Nouvelle Vague francesa y el Free Cinema inglés. En Italia brillan ilustres herederos del Neorrealismo como Antonioni o Pasolini. (GARCÍA PINO, 2009)

Desde esta primera película se advierte el interés del director por abordar el papel de la Universidad en la sociedad, como se manifiesta también en Del amor y otras soledades, Los paraísos perdidos (1985) y Octavia (2002). En las dos últimas, la Universidad de Salamanca vuelve a ocupar un lugar principal en las circunstancias y el destino de sus personajes, quienes, además, suelen tener una compleja relación con el entorno de donde proceden, cuestionándose el lugar que ocupan y su pertenencia al mismo. En este sentido, en lo referente a los espacios, el cineasta tiende a plasmar su ciudad natal en los filmes que realiza, aunque en Madrid también se enmarcan varios de ellos.

Así, Salamanca "es la ciudad más significativa por los sentimientos que le vinculan a la ciudad, una mezcla de amor y odio; amor a la belleza de sus edificios y la calma de sus espacios rurales, mientras que el disgusto responde a la aversión por el ambiente 
conservador" (GARCÍA DE LA RIVA, 2016, p. 279). Esto evidencia que en sus obras la idea de espacio está ligada, en primer lugar, a la psicología de los personajes, para, posteriormente, presentar los espacios físicos por donde transitan. Por ello, la elección de los mismos refuerza la naturaleza dramática de los seres de ficción, estableciéndose una estrecha y compleja relación entre el espacio mental de los protagonistas y el espacio físico.

Antes del rodaje, la productora Eco Films solicitó la etiqueta de 'Interés especial' para el filme, una distinción que finalmente fue concedida y le proporcionó "la máxima protección económica del Ministerio" (GARCÍA MARTíNEZ, 2005, p. 77). Del mismo modo, para evitar problemas con la censura, "el director salmantino se las arregló para cambiar los tres títulos de las últimas cartas sustituyendo '7. Guerra' por '7. Pretérito imperfecto', ‘8. Posguerra' por ‘8. Tiempo de silencio' y ‘9. Los aires de la paz' por ‘9. Un mundo feliz'” (VESGA NARANJO, 2016, p. 410).

Con ello, aludía a referentes literarios de notable significado en la película para enmascarar los aspectos políticos de los títulos iniciales, que podían resultar incómodos para el régimen. En cuanto al reconocimiento obtenido, Nueve cartas a Berta fue distinguida con la Concha de Plata en el Festival Internacional de Cine de San Sebastián y se convirtió en una de las películas más impactantes del NCE, logrando además "una recaudación de 7 millones de pesetas solo en el año de su estreno" (ARAGÜEZ RUBIO, 2006, p. 90); sin duda, todo un éxito tratándose de un filme que no se enmarcaba en el cine comercial que se distribuía por las salas de todo el país. Asimismo, supuso el lanzamiento de Emilio Gutiérrez Caba, quien solo había participado previamente en dos películas, la comedia musical protagonizada por Rocío Dúrcal Tengo 17 años (José María Forqué, 1964) y la citada obra del NCE La caza.

\subsection{Nueve cartas a Berta (1966) 5.1.1. El argumento}

Con una estructura narrativa novedosa compuesta por nueve episodios, y sus respectivos títulos, que dan lugar a las nueve cartas del filme, la ópera prima del cineasta salmantino está considerada una de las películas más representativas del NCE y una de las 
más críticas con el franquismo en los años 60. La historia se centra en Lorenzo Carvajal interpretado por Emilio Gutiérrez Caba-, un joven estudiante salmantino que acaba de regresar de Londres, donde ha pasado el verano. Allí se ha enamorado de la hija de un profesor español exiliado, Berta, quien ya ha nacido en el extranjero y le resulta muy diferente de las mujeres de su entorno. Retomar la rutina en Salamanca se le hace cuesta arriba, a pesar de contar con la compañía de sus amigos y de su novia -a quien da vida Elsa Baeza-, de manera que decide evadirse escribiendo sobre la realidad burguesa y provinciana que le rodea y sobre sus sentimientos hacia Berta.

Durante su estancia en Inglaterra descubre que hay otras formas de vida y empieza a cuestionarse el tipo de familia tradicional y de sociedad a la que pertenece. Así, a través de la voz en off expresa su hartazgo por las marcadas pautas sociales y el conservadurismo, mientras va contándole a Berta cómo es la España a la que pertenecen sus progenitores encarnados por Antonio Casas y Mary Carillo-, y en la que él se siente extraño. Su vacío existencial no tarda en convertirse en motivo de preocupación para su familia y para su novia. Por ello, realiza un retiro espiritual, del que se escapa a Madrid para visitar a unos amigos franceses que también conocen a Berta, aunque allí se da cuenta de que carece del bagaje cultural y del aperturismo mental de ellos. Posteriormente, se va a pasar una temporada con unos familiares a un pueblo de la sierra, donde observa que las diferencias sociales y económicas con la ciudad son abismales. Este viaje hacia la esencia rural logra reconfortarlo, así que, al volver a casa, inicia un acercamiento con sus padres -quienes han comprado un televisor, un rasgo de la bonanza burguesa-, y con su novia. De esta manera, claudica, al ver en Mari Tere y en su carrera de Derecho los motivos para llevar una vida como la de sus padres, práctica, alejándose de los ideales culturales que le seducían.

\subsubsection{Los profesores}

Los profesores que aparecen en la película son personajes secundarios, pero resultan de vital interés para la evolución de Lorenzo y para evidenciar el prototipo de docente universitario de la época. No obstante, aparecen cuatro profesores de diferentes edades que desempeñan roles distintos y que pueden clasificarse en cuatro niveles: el 
anciano profesor, el intelectual exiliado, el catedrático y el docente que lleva poco tiempo en la Universidad. Además, poseen un aspecto, un discurso, una forma de relacionarse, una posición social y un rol totalmente distintos.

El primero de ellos es un anciano profesor que aparece en la carta 4, 'La noche' , y que viene del exilio para dar una conferencia en la Universidad, sintiendo una considerable nostalgia al pisar las calles de Salamanca. De hecho, ve la ciudad "como el remanso de paz que abandonó a causa de la guerra: recuerda sus años en la universidad; a su célebre mentor -posiblemente Unamuno-; e idealiza el lugar al modo de Fray Luis" (MONTES ESPEJO, 2015, p. 440). La apariencia de este profesor es enjuta y avejentada, pues, además, lleva un sonotone, pero, sin embargo, posee un discurso academicista y totalmente lúcido. Imparte una brillante conferencia sobre el Humanismo, que, a pesar de ello, no congrega a muchos estudiantes, lo que obliga al joven profesor Astudillo -quien ha organizado el evento académico que preside el catedrático con el que trabaja en el departamento, Don Álvaro-, a animar a los alumnos y alumnas presentes -entre los que está Lorenzo-, a que lo saluden y le hagan preguntas. Posteriormente, durante la cena y el paseo que da con ellos, habla de Huxley, de Cervantes y de Unamuno, al que evoca con nostalgia al pasar por la que era su casa.

En cuanto a su forma de relacionarse, recibe las alabanzas de unos docentes que lo adulan, ante el pasotismo de los pocos estudiantes presentes. Además, estos empiezan a cuestionar su éxito, pues perciben que, aunque viva en el extranjero, no se ha enriquecido económicamente, llegando a pensar que en España le hubiera ido mejor a ese respecto. Lo que ellos no comprenden es que quizá ese profesor, de haberse quedado, no hubiera podido ejercer su libertad de cátedra en la Universidad. Así, advierten que la riqueza intelectual no está vinculada con el dinero. Por último, este profesor ejerce un rol de dominio, aunque sea de forma involuntaria, con respecto a unos profesores salmantinos tan ávidos de su sabiduría como de posicionarse junto a él para conseguir poder con respecto a sus iguales. Sin duda, se trata de un esquema piramidal muy reconocible a pesar del tiempo transcurrido.

\footnotetext{
${ }^{1}$ Se desarrolla del minuto 0:21:44 al minuto 0:28:56 de la película.
} 
En segundo lugar, este profesor nombra a José Carballeira, el padre de Berta, cuando Lorenzo le pregunta si lo conoce. El docente le cuenta que ambos coincidieron en la Residencia de Estudiantes de Madrid, que es alguien sorprendente y que, precisamente, acaba de escribir una recesión sobre su último libro. Por ello, le dice al catedrático salmantino que va en el grupo que también debería conocerlo, a lo que este responde con cierto reparo alegando que su última obra ha sido un ensayo sobre la poesía en el exilio. Con estas palabras, el catedrático deja claro que en España existen reticencias a establecer relaciones con alguien de su perfil, es decir, que se exilió en Londres por su militancia republicana. Sin embargo, el docente destaca el notable estudio que Carballeira realizó sobre La Celestina, que fueron muy amigos en Madrid, que le escribió cuando le reconocieron en la Universidad de Harvard, y, también, que es un trabajador incansable, emprendedor y abierto.

Aunque su imagen no aparece en la pantalla, pues solo se conoce lo que Lorenzo y este opinan de él, se constata que posee un discurso culto que causa admiración y respeto en el ámbito literario. Además, consiguió entrar en una elite intelectual y cultural en el extranjero. Su nombre está en la dedicatoria de un libro que Lorenzo se trae de Londres y que aparece justo debajo de unos versos de Antonio Machado que aluden a la Guerra Civil, y que alertan a su padre. Lorenzo recuerda también su importante biblioteca y que Berta le ayudaba con la revisión de sus escritos, algo que a él le hubiera gustado hacer. En este sentido, Carballeira "adquiere un aura mística para Lorenzo, quien en Madrid busca sus raíces visitando su antigua casa" GARCÍA DE LA RIVA, 2016, p. 428), situada en la Calle Alfonso XIII, pero que, sin embargo, ahora es la sede de una empresa petrolera de Estados Unidos.

En tercer lugar, el catedrático Don Álvaro es el profesor que menos presencia tiene en la trama, pero posee unos rasgos bastante reseñables. Aunque también es mayor, pero no tanto como el primero, posee un aspecto elegante y una pose distante con la que marca su estatus ante los demás, especialmente con Astudillo. Además, se percibe que se sitúa próximo a la ideología imperante, tanto por sus reticencias a Carballeira, como por la admiración que exhibe, durante el citado paseo y mirando la fachada de la Catedral Nueva, por el descubrimiento y la conquista de América -dos hechos históricos ensalzados durante 
el franquismo-, y por los teólogos de la Contrarreforma. Asimismo, y aunque paga la cena del conferenciante, no le presta demasiada atención durante la caminata posterior, ya que parece más interesado en comentar a los pocos alumnos que les acompañan los detalles de los edificios salmantinos más monumentales, de los que dice incluso que ni Italia tiene rincones semejantes.

Con ello, demuestra que es un hombre conservador a nivel ideológico, defensor del firme catolicismo que propugna el régimen y un apasionado de la riqueza y del patrimonio histórico de la ciudad. Este personaje posee un nivel económico y social elevado, pues goza de reconocimiento en la Universidad y en la sociedad a la que pertenece, a pesar de que no es tan brillante como el anciano profesor y como Carballeira. Este detalle pone de relieve que, con su nivel cultural y su afinidad al régimen, su situación y su promoción dentro de la Universidad española de la época puede haber sido más fácil que la de un profesor que tuviera otras ideas, aunque fuera un intelectual.

En cuarto lugar, el Profesor Ayudante Ricardo Astudillo aparece junto al protagonista en la carta 8, "Tiempo de silencio"2, aunque ya había estado presente durante la conferencia del profesor exiliado y el posterior paseo nocturno. Representa a un tipo de docente "que está más próximo al anciano y al joven, que al catedrático al que le debe pleitesía" (MONTES ESPEJO, 2015, p. 440), evidenciando la incipiente existencia de un nuevo modelo para la época. Por ello, a la vez que muestra admiración y respeto por el anciano profesor -como expresa en su atenta forma de escucharlo-, parece también muy cercano a los alumnos, como se pone de manifiesto con Lorenzo en la narración de esta carta.

En esta secuencia, ve al joven abatido en el claustro, quien se encuentra perdido porque sigue sin encontrar su sitio en Salamanca y en su familia, y directamente le pregunta si se encuentra bien. Aunque él le responde -para salir del paso-, que solo está algo mareado, el profesor le confiesa que hacía días que no lo veía, indicando así que se fija en sus alumnos y que, para él, no son un número, como sí le ocurre a los profesores más veteranos. Lorenzo le dice que no pudo presentarse al parcial de su asignatura, pidiéndole

\footnotetext{
${ }^{2}$ Se desarrollo del minuto 1:12:08 al minuto 1:13:08 de la película.
} 
hasta disculpas por ello, pero Astudillo, lejos de sentirse molesto, le recomienda que se siente en el banco de la galería para que se recupere, o que pase a su despacho si lo necesita, pues allí tiene un diván. Lorenzo rechaza esta propuesta y se sienta en el banco, pero, debido a la cara pálida que tiene, el docente toca su frente para comprobar si tiene fiebre. Posteriormente, bajan por la escalera y Astudillo le propone ir juntos al bar de la Facultad a tomar unas copas para que pueda despejarse. De camino, le pide que le tutee y que se cuide, y, para acercarse un poco más a él, le dice que se acuerda de que una vez escribió en una revista. Con esta actitud, se observa que este profesor no sólo está centrado en el mundo académico en el que se basan sus clases, sino también en las personas que las conforman y a las que se dirige.

\subsubsection{Los estudiantes}

Los alumnos que aparecen en la película se mueven en un ambiente marcado por dos pilares que regían la vida durante el franquismo, la familia y la religión, pero también por otro de perfil educativo y cultural como la Universidad. Aunque esta institución ha tenido siempre una considerable influencia en Salamanca, y en su sociedad, Patino la presenta con un carácter opresivo. Así, muestra "una institución universitaria restrictiva y elitista, cuyo espacio se limita a las clases privilegiadas, a las élites intelectuales, sociales y políticas, cerrada al pensamiento libre" GARCÍA DE LA RIVA, 2016, p. 431). Esta idea se percibe en los estudiantes que ocupan sus aulas, quienes proceden de familias burguesas de la propia ciudad, de otras ciudades o de zonas rurales y comparten un asentado conservadurismo que está instalado en la forma en que entienden la realidad. Además, se mueven en un ambiente universitario donde predomina "una vida de picaresca, costumbrista, llena de tipos [... ] que solo se aplican para mantener una beca y conseguir a toda costa la garantía de ser funcionario" (MONTES ESPEJO, 2015, pp. 439).

A este respecto, el mejor amigo de Lorenzo, Benito, se erige como un claro prototipo, pues vive en una pensión para estudiantes, tiene una visión muy práctica de la vida y de cómo va a ser su futuro, no tiene un gran interés por la cultura y, además, le habla al protagonista de cómo debería ver las cosas. En definitiva, Benito “representa al típico 
estudiante provinciano y acomodado" GARCÍA DE LA RIVA, 2016, p. 428), y encarna el perfil universitario predominante. Empero, Lorenzo descubre en Madrid otro totalmente opuesto a través de su amigo francés Jacques y de sus compañeros, quienes son cosmopolitas, viajan, hablan idiomas y escuchan jazz.

En cuanto a las alumnas, la película muestra el colegio religioso donde vive Mari Tere -'La Residencia Femenina Virgen del Puerto'-, regido por unas monjas que mantienen un férreo horario en lo que respecta a las salidas de las chicas. De hecho, Lorenzo y Mari Tere tienen que correr tras algunos de sus paseos vespertinos para que la joven no se pase de la hora límite. Para el protagonista, Mari Tere le recuerda a su madre, pues se preocupa por él de forma maternal -intuyendo como podría ser su perfil como esposa-, mientras que a Berta la ve culta, cosmopolita e independiente. A este respecto, Lorenzo es consciente del sacrificio que hace su progenitora.

Por este motivo, le dice a Berta: "Yo solo desearía para ti que fueses un poco más feliz que ella, más sincera, como menos esclava, más independiente, no sé cómo decirte... más libre"3. A pesar de sus estudios, se percibe que Mari Tere puede convertirse en una ama de casa burguesa, que no ejerza su profesión, y que, como su futura suegra, tenga servicio doméstico en casa. De esta manera, los roles tradicionales están condenados a volver a repetirse. Por otra parte, la película muestra una figura de cierta relevancia en el ámbito estudiantil de la época, la madrina de la tuna, de los estudiantes y de la Universidad, quien aparece en una de las fiestas donde, a modo de guateque, los chicos y las chicas bailan las canciones del momento. Desde el escenario, la joven dice sonriente a los asistentes: "Yo ahora en realidad no estudio desde que dejé el colegio. Además, como voy a casarme pronto..."4, evidenciando la situación de muchas chicas.

Con respecto a la dinámica docente, se observa una hegemonía de las clases magistrales en la que unos profesores normalmente muy mayores imparten los conocimientos de una forma clásica y monótona, sin tener prácticamente interacción con el alumnado. Lo mismo sucede en la conferencia del catedrático a las que los estudiantes

\footnotetext{
3 Lorenzo pronuncia estas palabras del minuto 0:10:54 al minuto 0:11:05 de la película.

${ }^{4}$ La madrina universitaria pronuncia esta frase del minuto 0:13:00 al minuto 0:13:08 de la película.
} 
asisten, pues lo escuchan con respeto $y$, posteriormente, lo acompañan junto a sus profesores en el paseo nocturno anteriormente citado. Aquí es donde se produce un cierto acercamiento entre el profesorado y sus pupilos, quienes se atreven a hablar con el profesor exiliado, como demuestra Lorenzo.

No obstante, la parte lúdica de la vida estudiantil también es representada en el filme, sobre todo, en la fiesta mencionada, donde destaca la presencia de la tuna amenizando la velada. Por otra parte, estos tunos visitan una escuela rural para interpretar ante los niños, la maestra y, en definitiva, los vecinos, algunos de sus temas típicos, como el célebre 'Fonseca', tras la participación de un grupo local de coros y danzas. Esta actuación forma parte de las actividades de la excursión que promueve la prima del protagonista, y a la que él va porque era el único que sabía manejar el proyector de cine en el colegio. Esta actividad revela el papel educativo y socializador tan importante que tenía el cine en las zonas más deprimidas, como demostraron los pioneros de las Misiones Pedagógicas durante la Segunda República Española (OTERO URTAZA y GARCÍA ALONSO, 2006). En la excursión se constatan las profundas diferencias existentes entre los jóvenes de la capital y los del pueblo, y, especialmente, el aspecto curtido y ajado de las personas mayores con respecto a los padres de Lorenzo o sus profesores, por ejemplo. A nivel educativo, resulta de interés ver el mobiliario de la clase rural, con sus mapas, pizarra, crucifijo y la foto de Franco.

\subsubsection{El espacio}

Salamanca aparece como protagonista espacial de la película, aunque la imagen que se ofrece de ella no se centra en ensalzar su nutrido patrimonio histórico-artístico y monumental, sino en presentar a su sociedad tradicional y provinciana, donde lo principal es guardar las apariencias. De esta manera, la ciudad castellana se erige como un modelo de las pequeñas y medianas urbes españolas de los 60, donde el desarrollismo no se percibía como en las grandes capitales y el conservadurismo dominaba el devenir social de sus ciudadanos. Por este motivo, se puede indicar que "el homenaje artístico patente desde el prisma visual se convierte en un homenaje crítico a través de las connotaciones desaprobadoras 
a la sociedad recreada por Basilio Martín Patino en su ciudad natal” (SÁNCHEZ RODRÍGUEZ, 2016, p. 76).

De todas formas, se muestran diversas calles de la parte antigua, la Plaza Mayor, la parte exterior de las dos catedrales, la Universidad Pontificia, la Iglesia de San Esteban, la Casa de las Conchas o el puente romano, entre otros lugares reconocibles de la ciudad. Además, Lorenzo le habla a Berta en sus cartas de la monumentalidad salmantina, de sus edificios históricos y de que transitaron por sus calles personajes literarios como La Celestina o el Lazarillo de Tormes, y escritores como Fray Luis de León o Cervantes. Esto evidencia que el protagonista, a pesar de que se queja de la poca vida que tiene la ciudad, sigue cautivado por su esplendoroso pasado. Se produce así una mitificación del espacio, pues, realmente, Salamanca continúa anquilosada en una estampa decimonónica, como revela Patino al congelar ciertas imágenes de la película. Así, la sensación de que el tiempo se ha detenido para quienes habitan en la ciudad castellana durante los 60 se refleja también en el montaje, potenciando esta idea a los espectadores:

Fotografiados con claridad, sin efectos lumínicos, vemos calles, monumentos, plazas emblemáticas de la ciudad por donde se cuelan personajes reales que ignoran formar parte de una película de ficción: los alféreces en la Plaza Mayor o los grupos de curas sorprendidos en las caminatas de Lorenzo; aspectos que refuerzan el aliento neorrealista que impulsa al film. (GARCÍA MARTíNEZ, 2005, p. 82)

Por el contrario, Londres aparece en el relato de Lorenzo como un ejemplo de libertad y de modernidad, es decir, como la antítesis de Salamanca, mientras que Madrid es presentada como una ciudad dinámica y bulliciosa. Aquí es “donde Lorenzo podría haberse liberado, vivir en residencias libres del control religioso de los colegios mayores, y donde incluso proyectaban Las Hurdes, mientras que en provincias los jóvenes eran fans de Marisol" (MONTES ESPEJO, 2015, p. 442). Este documental de Luis Buñuel5 indica que en la capital española ya se exhibían filmes críticos en ciertos circuitos culturales. Además, el

\footnotetext{
${ }^{5}$ Las Hurdes (Tierra sin pan) (Luis Buñuel, 1933). En esta cinta, el cineasta aragonés realizó una crítica "contra la extrema miseria de una comarca extremeña” (OTERO URTAZA y GARCÍA ALONSO, 2006, p. 387).
} 
café de Madrid repleto de jóvenes con inquietudes al que el protagonista va con sus amigos franceses contrasta con el principal lugar de reunión en Salamanca: el cada vez más rancio casino. En cuanto a la vinculación del espacio urbano con la influencia del régimen, tan presente en la película a través de religiosos y de las fuerzas del orden, se puede afirmar que Salamanca "simboliza a la España franquista que coarta cualquier intento de libertad personal" (GARCÍA DE LA RIVA, 2016, p. 424).

\section{Conclusiones}

La mirada del cine hacia la educación, o la historia de la educación, suele constituir una interesante representación simbólica de la realidad de los docentes, los alumnos o los espacios educativos. En el cine español el mundo de la infancia y de los entornos escolares son los que se han tratado en más películas, sobre todo durante el franquismo, siendo la etapa comprendida entre la segunda mitad de la década de los 50 y la primera mitad de la de los 60, la más prolífica. Durante esta década, Pablito Calvo, Joselito, Marisol y Rocío Dúrcal fueron los niños prodigio que más filmes protagonizaron, muchos de ellos centrados en el mundo de la educación. Estos títulos plasmaron a profesores religiosos, maestros de escuelas rurales, institutrices extranjeras o la vida en internados selectos. La imagen amable de la educación que presentaban era opuesta a la que en 1955 ofreció Juan Antonio Bardem en Muerte de un ciclista, en este caso sobre la Educación Superior. De esta manera, el tratamiento de la educación durante el franquismo, y concretamente durante el periodo indicado, oscila entre la edulcoración proyectada en el cine comercial y el espíritu realista de los cineastas más críticos con el régimen.

La representación de la Universidad en el cine español estuvo en estos años más próxima a la primera tendencia que a la segunda, a pesar de la mirada tan interesante que Bardem ofreció en una película que incluso proyectó en una secuencia las primeras protestas estudiantiles. Sin embargo, fue en el cine comercial donde pocos años después surgieron filmes centrados en este ámbito, eso sí, con un marcado tono de evasión y sin potenciar el espíritu crítico. Se trataba de títulos enfocados al gran público en los que se 
presentaban de forma cómica la llegada de la mujer a las aulas universitarias y las tentaciones de la vida estudiantil, como Margarita se llama mi amor o Los chicos del Preu, pero que también reflejaban el esfuerzo de las familias españolas por enviar a sus hijos a la Universidad. Además, sus tramas potenciaban las relaciones amorosas entre los personajes y ofrecían una imagen amable de la dictadura.

En este contexto marcado por el desarrollismo, las películas del Nuevo Cine Español consiguieron mostrar una mirada de la Universidad más realista y más crítica, al estilo de Bardem, como se advierte en Nueve cartas a Berta. Sin duda, "este cine conseguía lanzar veladas críticas y exámenes morales contra el Régimen, siempre alerta a la hora de cortar alas a estas licencias" (BRAVO, 2000, p. 151). A pesar de la censura vigente, los festivales internacionales premiaron a varias de estas películas, estableciéndose así una dicotomía entre el cine que apoyaba el régimen y que no solía atraer al ámbito internacional, y el que criticaba la dictadura y obtenía el reconocimiento extranjero.

Nueve cartas a Berta es un filme de referencia del NCE y se erige como un espejo de la vida provinciana española de los 60 , constituyendo, además, una crítica a la sociedad franquista. Está más próxima a Muerte de un ciclista que al cine comercial por la crítica social que posee y por el tratamiento que realiza de la Universidad, mucho más realista y desencantado. Además, muestra la crisis personal en la que se encuentra el protagonista tras conocer cómo es la vida en Londres, más libre y menos influida por los convencionalismos sociales. Martín Patino decidió insertar imágenes congeladas de aspectos de la vida salmantina para indicar que el tiempo en Salamanca se ha detenido durante el franquismo, como si siguiera todavía en el siglo XIX. Con ello, se acentuaba a nivel espacial las diferencias entre la capital británica y la ciudad castellana.

Asimismo, la película resulta muy significativa por los diferentes prototipos de profesores que presenta. En su construcción priman dos aspectos decisivos: la ideología y la carrera académica. Resulta interesante observar que los profesores españoles exiliados -el anciano conferenciante y Carballeira-, son mostrados como intelectuales que se mueven en círculos culturales europeos y que los profesores de la Universidad de Salamanca viven de una forma burguesa -sobre todo el catedrático, Don Álvaro-, pero 
carecen de la brillantez académica de los anteriores. Quizá el personaje que indica la paulatina llegada de un nuevo perfil de docente sea Astudillo, quien se muestra atento con el conferenciante exiliado, respetuoso con el catedrático para el que trabaja y cercano con los estudiantes. Sin duda, refleja una cierta ruptura en la verticalidad imperante de la estructura universitaria. Por este motivo, se puede afirmar que Astudillo encarna un nuevo prototipo de profesor universitario en la década de los 60 que tendría un mayor protagonismo en el tardofranquismo y, posteriormente, en la Transición.

En cuanto al alumnado, la película tiene más escenas fuera de las aulas que dentro de ellas, y esto permite observar las relaciones entre chicos y chicas en los momentos de ocio. Así se percibe en los guateques con la tuna, en la excursión a un pueblo con el proyector de cine, o, especialmente, en los paseos y conversaciones de Lorenzo y de Mari Tere. Mientras que Berta es tratada de una forma casi idealizada, Mari Tere es para el protagonista una chica que pronto se convertirá en alguien como su madre: una mujer burguesa, católica, de buena posición social, atenta con su familia y servil con su marido. Martín Patino establece que los roles masculinos y los femeninos están muy delimitados en la España del franquismo, a pesar de que las chicas estaban cada vez más presentes en la universidad.

Por ello, se establece un paralelismo entre la relación matrimonial de los padres de Lorenzo y la relación del joven con su novia, pues a pesar de ilusionarse con Berta y con lo que ella representa, parece abocado a unirse a Mari Tere para imitar el patrón de sus progenitores en la hermética sociedad de Salamanca. La elección de la Universidad de Salamanca -la más antigua de España, fundada en 1218-, para el desarrollo de la historia, la apuesta por mostrar distintos perfiles de profesores universitarios y la construcción de un estudiante protagonista -que expresa sus inquietudes y dudas por la carrera que estudia y por la vida que le espera cuando la termine en una ciudad donde todo parece estar controlado-, hacen posible que Nueve cartas a Berta sea una película muy interesante para aproximarse a la realidad universitaria española de los años 60. Esto evidencia la apuesta del NCE por construir historias más apegadas a la vida cotidiana y críticas con la sociedad del franquismo, en las que la evasión propia del cine comercial es sustituida por la reflexión del espectador. 


\section{Referencias}

ARAGÜEZ RUBIO, Carlos. La política cinematográfica española en los años sesenta: la propaganda del régimen a través del nuevo cine español (1962-1967). Sociedad y Utopía. Revista de Ciencias Sociales, n. 27, 2006, p. 77-92. Recuperado de: http://www.sociedadyutopia.es/index.php/revistas-publicadas.

BELLO CUEVAS, José Antonio. 50 años del “Nuevo Cine Español”. Un recorrido por la cinematografía del último medio siglo. Aularia. El país de las aulas, vol. 2, 2014, p. 27-34. Recuperado de: https://www.aularia.org/Articulo.php?idart=168\&idsec $=5$.

BERMÚDEZ DE CASTRO, Ramiro (Productor) y MARTíN PATINO, Basilio (Director). Nueve Cartas a Berta. España: ECO Films/ Transcontinental Films Española S.A., 1966.

BRAVO, Laura. La adopción literaria del "nuevo cine español”. Anuario del Departamento de Historia y Teoría del Arte de la Universidad Autónoma de Madrid, n. 12, 2000, pp. 145154. Recuperado de: https://repositorio.uam.es/handle/10486/1003.

DURÁN MANSO, Valeriano. Los niños prodigio del cine español: aproximación a la educación de los años 50 y 60 . Ridphe_R Revista lberoamericana do Patrimônio Histórico-Educativo, 1, 2015, p. 128-145. Recuperado de:

https://econtents.bc.unicamp.br/inpec/index.php/ridphe/article/view/9233/4657.

DURÁN MANSO, Valeriano y ÁLVAREZ DOMÍNGUEZ, Pablo. La imagen de la escuela en la primera etapa del cine español del franquismo: autarquía, patriotismo y nacionalcatolicismo (1939-1950). Revista Educació i Història: Revista d'Història de l'Éducació, n. 31, 2018, p. 59-88. Recuperado de:

http://revistes.iec.cat/index.php/EduH/article/view/144072/142723.

ESCRIVÁ, Vicente (Productor) y FERNÁNDEZ, Ramón (Director). Margarita se llama mi amor. España: ASPA Producciones cinematográficas, 1961.

GARCÍA DE LA RIVA, Andrés. Los espacios perdidos. Acercamiento a los espacios en la obra audiovisual de Basilio Martín Patino. Tesis doctoral. Logroño: Universidad de La Rioja, 2016. Recuperado de: https://dialnet.unirioja.es/servlet/tesis?codigo $=48478$.

GARCÍA MARTÍNEZ, Alberto Nahum. Realidad y representación en el cine de Basilio Martín Patino: montaje, falsificación, metaficción y ensayo. Tesis Doctoral. Pamplona: Universidad de Navarra, 2005. Recuperado de:

https://dadun.unav.edu/handle/10171/34244. 
GARCIA PINO, Gonzalo. Pionero Patino. Revista Minerva: Revista del Círculo de Bellas Artes. Madrid: Círculo de Bellas Artes, n. 10, 2009. Recuperado de: http://www.circulobellasartes.com/revistaminerva/articulo.php?id=301\#.

GIL, Alberto. La censura cinematográfica en España, Barcelona, Ediciones B, 2009. GONZÁLEZ GARCÍA, Fernando. Basilio Martín Patino: pensar la historia. Film-Historia. Barcelona: Universidad de Barcelona, n. 2, vol. VII, pp. 141-170, 1997. Recuperado de: http://revistes.ub.edu/index.php/filmhistoria/article/view/12348/15108.

GOYANES, Manuel (Productor) y BARDEM, Juan Antonio (Director). Muerte de un ciclista. España/ Italia: Guión Producciones Cinematográficas/ Suevia Films-Cesáreo González/ Trionfalcine, 1955.

LAMET, Juan Miguel (Productor) y MARTÍN PATINO, Basilio (Director). Del amor y otras soledades. España: Cesáreo González Producciones Cinematográficas/ Eco Films, 1969).

LUCIA, Luis (Director). Canción de juventud [Cinta cinematográfica]. España: Procusa/ Época Films, S.A., 1961.

MARTÍNEZ CARAZO, Piedad Cristina. El método de estudio de casos. Estrategia metodológica de la investigación científica. Pensamiento y gestión, n. 20, 2006, p. 165193.

MASÓ, Pedro (Productor) y LAZAGA, Pedro (Director). Los chicos del Preu. España: C. B. Films S.A./ Pedro Masó P.C., 1967.

MONTERDE, José Enrique. Continuismo y disidencia (1951-1962). En GUBERN, Roman; MONTERDE, Jósé Enrique; PÉREZ PERUCHA, Julio; RIAMBAU, Esteve; y TORREIRO, Casimiro (Coords.). Historia del cine español. Madrid: Ediciones Catedra, 2005, p. 239-293.

MONTES ESPEJO, Anna. 9 cartas a Berta o la confirmación del no lugar del intelectual en España. En: CAMARERO, E. y MARCOS, M. (Coords.) III Congreso Internacional Historia, Literatura y Arte en el Cine en español y portugués. Hibridaciones, transformaciones y nuevos espacios narrativos. Salamanca: Centro de Estudios Brasileños. Universidad de Salamanca, Tomo I, 2015, p. 434-450. En línea:

https://congresocinesalamanca2015.files.wordpress.com/2015/10/salamanca-actas-tomo1.pdf.

OTERO URTAZA, Eugenio y GARCÍA ALONSO, María. Las Misiones Pedagógicas (19311936). Madrid: Sociedad Estatal de Conmemoraciones Culturales/ Residencia de Estudiantes, 2006.

PÉREZ MILLÁN, Juan Antonio; PÉREZ MORÁN, Ernesto. Cien profesores universitarios en el cine de ayer y de hoy. Salamanca: Ediciones Universidad de Salamanca, 2015. 
SÁNCHEZ BOROX, Juan. Basilio Marín Patino. Memoria, disidencia y realidad. Tesis doctoral. Cuenca: Universidad de Castilla-La Mancha, 2015. Recuperado de: https://ruidera.uclm.es/xmlui/handle/10578/6593.

SANCHEZ NORIEGA, José Luis. Historia del Cine. Teoría y géneros cinematográficos, fotografía y televisión. Madrid: Alianza Editorial, 2005.

SÁNCHEZ RODRÍGUEZ, Virginia. Salamanca: enclave cinematográfico y cuna de profesionales de la industria fílmica y musical en el desarrollismo (1959-1975). Revista de Comunicación de la SEECI, n. 41, año XX, p. 66-81, 2016. Recuperado de: http://www.seeci.net/revista/index.php/seeci/article/view/427/pdf_157.

TORREIRO, Casimiro. ¿Una dictadura liberal? (1962-1969). En: GUBERN, Román; MONTERDE, Jósé Enrique; PÉREZ PERUCHA, Julio; RIAMBAU, Esteve; y TORREIRO, Casimiro (Coords.). Historia del cine español. Madrid: Ediciones Cátedra, 2005, p. 295-340.

VESGA NARANJO, Catalina. Las vanguardias musicales en el Nuevo Cine Español (60s, 70s, 80s). Percepción y universales culturales a través del análisis de sus bandas sonoras. Tesis Doctoral. Madrid: Universidad Complutense de Madrid, 2016. Recuperado de: https://eprints.ucm.es/39211/.

Recebido em: 11/03/2020 Aprovado em: 10/06/2020

Universidade do Estado de Santa Catarina - UDESC Programa de Pós-Graduação em Educação - PPGE 